\title{
Мощные GaN-транзисторы с подзатворной областью на основе МДП-структур
}

\author{
(C) Е.В. Ерофеевв ${ }^{1}$, И.В. Федин ${ }^{2}$, В.В. Федина ${ }^{2}$, М.В. Степаненко ${ }^{2}$, А.В. Юрьева ${ }^{3}$ \\ ${ }^{1}$ Научно-исследовательский институт систем электрической связи \\ Томского государственного университета систем управления и радиоэлектроники, \\ 634034 Томск, Россия \\ ${ }^{2}$ АО Научно-производственная фрирма „Микран“, \\ 634045 Томск, Россия \\ ${ }^{3}$ Физико-технический институт \\ Национального исследовательского Томского политехнического университета, \\ 634050 Томск, Россия \\ E-mail: erofeev@micran.ru
}

(Получена 1 марта 2016 г. Принята к печати 10 марта 2017 г.)

\begin{abstract}
Транзисторы с высокой подвижностью электронов на основе эпитаксиальных гетероструктур AlGaN/GaN являются перспективной элементной базой для создания устройств силовой электроники следующего поколения. Это обусловлено как высокой подвижностью носителей заряда в канале транзистора, так и высокой электрической прочностью материала, позволяющей достичь высоких напряжений пробоя. Для применения в силовых коммутационных устройствах требуются нормально закрытые GaN-транзисторы, работающие в режиме обогащения. Для создания нормально закрытых $\mathrm{GaN}$-транзисторов чаще всего используют подзатворную область на основе $\mathrm{GaN} p$-типа, легированного магнием ( $p$-GaN). Однако оптимизация толщины эпитаксиального слоя $p$ - $\mathrm{GaN}$ и уровня легирования позволяет добиться порогового напряжения отпирания $\mathrm{GaN}$-транзисторов, близкого к $V_{\mathrm{th}}=+2 \mathrm{~B}$. В настоящей работе показано, что использование подзатворной МДП-структуры в составе $p$-GaN-транзистора приводит к увеличению порогового напряжения отпирания до $V_{\mathrm{th}}=+6.8 \mathrm{~B}$, которое в широком диапазоне будет определяться толщиной подзатворного диэлектрика. Кроме того, установлено, что использование МДП-структуры приводит к уменьшению начального тока транзистора, а также затворного тока в открытом состоянии, что позволит уменьшить потери энергии при управлении мощными GaN-транзисторами.
\end{abstract}

DOI: 10.21883/FTP.2017.09.44895.8569

\section{1. Введение}

Появившись в середине 70-х годов прошлого века силовые MOSFET транзисторы на основе кремния $(\mathrm{Si})$, благодаря большей скорости переключения и высокой эффективности по сравнению с биполярными транзисторами, стали повсеместно использоваться в силовой электронике: источниках питания, DC-DC преобразователях, контроллерах двигателей и пр. Однако сейчас, после непрерывного развития в течение более чем трех десятилетий, производительность Si MOSFET транзисторов достигла своего теоретического предела. Следующим шагом в развитии силовой электроники стало появление мощных транзисторов на основе нитрида галлия $(\mathrm{GaN})[1]$.

Уникальные физические характеристики нитрида галлия в сравнении с кремнием позволяют достигнуть значительных улучшений в производительности: понижение сопротивления открытого канала, рост скоростей переключения, сохранение надежности при высоких уровнях температуры и радиации, уменьшение размеров упаковки. Возможность очень быстрого переключения практически без потерь, появляющаяся при использовании $\mathrm{GaN}$-транзисторов, означает возможность увеличить эффективность и уменьшить размер преобразователя, а также уменьшить себестоимость его изготовления за счет отказа от ряда дорогостоящих пассивных элементов (фильтров) схемы.

Для применения в силовой электронике необходимы нормально закрытые $\mathrm{GaN}$-транзисторы, работающие в режиме обогащения. Для создания нормально закрытых $\mathrm{GaN}$-транзисторов чаще всего используют подзатворную область на основе GaN $p$-типа, легированного магнием $(p-\mathrm{GaN})[2,3]$.

При этом пороговое напряжение отпирания транзистора с подзатворной областью на основе $p$-GaN-определяется главным образцом толщиной эпитаксиального слоя $p-\mathrm{GaN}$ и уровнем его легирования. Оптимизация данных параметров позволяет добиться порогового напряжения отпирания $\mathrm{GaN}$-транзисторов, близкого к $V_{\mathrm{th}}=+2$ В. При этом максимально допустимое значение напряжения на затворе $p$-GaN-транзистора составляет всего $V_{g s \max }=6 \mathrm{~B}$, что делает их не совместимыми с работой типовых драйверов управления кремниевых MOSFET транзисторов, у которых уровень управляющего сигнала на выходе может достигать $V_{g s}=15 \mathrm{~B}$. Таким образом, актуальной является задача по повышению порогового напряжения отпирания силовых $\mathrm{GaN}$-транзисторов с подзатворной областью на основе $p$-GaN, а также увеличению максимально допустимого напряжения на затворе.

Известно, что нормально закрытые $\mathrm{GaN}$-транзисторы могут быть получены при использовании рецесса (уто- 
нения) барьерного слоя $\mathrm{AlGaN}$ с последующим формированием подзатворной МДП-области на основе тонких пленок $\mathrm{Al}_{2} \mathrm{O}_{3}$ или $\mathrm{Si}_{x} \mathrm{~N}_{y}$ диэлектриков [4-7], сформированных методами плазмохимического или атомнослоевого осаждения (ALD). K преимуществам таких транзисторов можно отнести высокое пороговое напряжение отпирания, близкое к $V_{\text {th }}=+5 \mathrm{~B}$, а также высокое значение максимального допустимого напряжения на затворе транзистора $\left(V_{g s}>10 \mathrm{~B}\right)$. Однако данные транзисторы характеризуются недостаточно высокой надежностью их работы, что обусловлено наличием дефектов травления на границе раздела диэлектрик/тонкий барьерный слой на основе $\mathrm{AlGaN}$ [8-10].

Цель настоящей работы заключается в исследовании электрических характеристик мощных $\mathrm{GaN}$-транзисторов с подзатворной МДП-областью при использовании $p$-GaN/AlGaN/GaN-структур.

\section{2. Методики эксперимента}

В экспериментах использовались эпитаксиальные гетероструктуры типа $p$-GaN/AlGaN/GaN, выращенные методом металлоорганической газофазовой эпитаксии на подложках кремния Si диаметром 100 мм. Гетероструктура включала в себя буферный слой на основе легированного железом GaN толщиной 2 мкм, канальный слой $\mathrm{GaN}$, барьерный слой $\mathrm{Al}_{0.25} \mathrm{Ga}_{0.75} \mathrm{~N}$ толщиной 10 нм и $p$-GaN-слой, легированный магнием. Толщина $p$-GaN слоя составляла 50 нм, концентрация атомов магния определялась вторичной ионной масс спектроскопией и составляла $5 \cdot 10^{19} \mathrm{~cm}^{-3}$.

На начальной стадии на поверхность пластин методом плазмохимического осаждения производилось осаждение тонких пленок диэлектрика на основе нитрида кремния $\left(\mathrm{Si}_{3} \mathrm{~N}_{4}\right)$ с толщинами $0.5,10$ и 15 нм. Далее литографическими методами производилось формирование рисунка затворной металлизации с последующим осаждением пленок палладия (Pd) толщиной 100 нм методом электронно-лучевого испарения в вакууме. Методом плазмохимического травления производилось удаление пленки $\mathrm{SiN}$ с поверхности пластин при использовании твердой маски на основе пленки палладия. Далее по Pd-маске производилось селективное плазмохимическое травление $p$-GaN-слоя в плазме состава $\mathrm{BCl}_{3} / \mathrm{SF}_{6}$ с целью формирования самосовмещенной подзатворной $p$-GaN области. После формирования межприборной изоляции на пластине производилось формирование низкотемпературных $\left(550^{\circ} \mathrm{C}\right)$ омических контактов на основе композиции $\mathrm{Ta} / \mathrm{Al}$ к областям стока и стока транзистора. Далее на поверхность пластин производилось плазмохимическое осаждение защитного диэлектрика на основе пленок нитрида кремния толщиной 170 нм.

Длина и ширина затвора $\mathrm{GaN}$-транзистора составляла 1 и 100 мкм соответственно. Расстояния затвор-исток и затвор-сток составляли 1 и 6 мкм.

Электрические параметры GaN-транзисторов по постоянному току исследовались с помощью измерителя характеристик полупроводниковых приборов HР4156А.

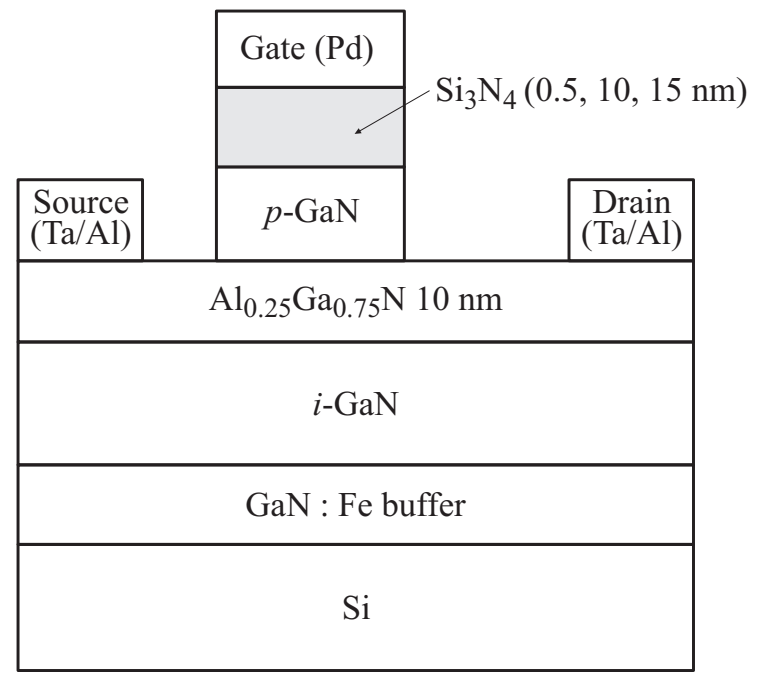

Рис. 1. Схематическое изображение изготовленного мощного GaN-транзистора с подзатворной областью на основе МДП-структур.

На рис. 1 представлено схематическое изображение изготовленного мощного GaN-транзистора с подзатворной областью на основе МДП-структур.

\section{3. Экспериментальные результаты и их обсуждение}

На рис. 2 представлены стоковые передаточные характеристики $\left(I_{d s}-V_{g s}\right)$ изготовленного мощного $\mathrm{GaN}$-транзистора с подзатворной областью на основе МДП-структур. Транзистор, изготовленный классическим способом с затвором на основе барьера Шоттки, демонстрирует нормально закрытый режим работы со значением порогового напряжения отпирания

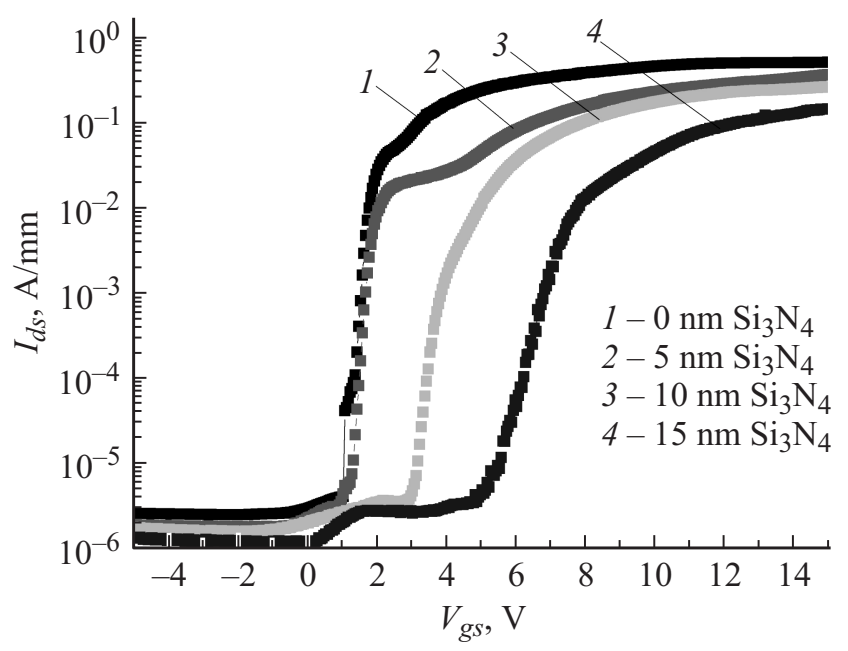

Рис. 2. Стоковые передаточные характеристики $\left(I_{d s}-V_{g s}\right)$ изготовленного мощного $\mathrm{GaN}$-транзистора с подзатворной областью на основе МДП-структур. 


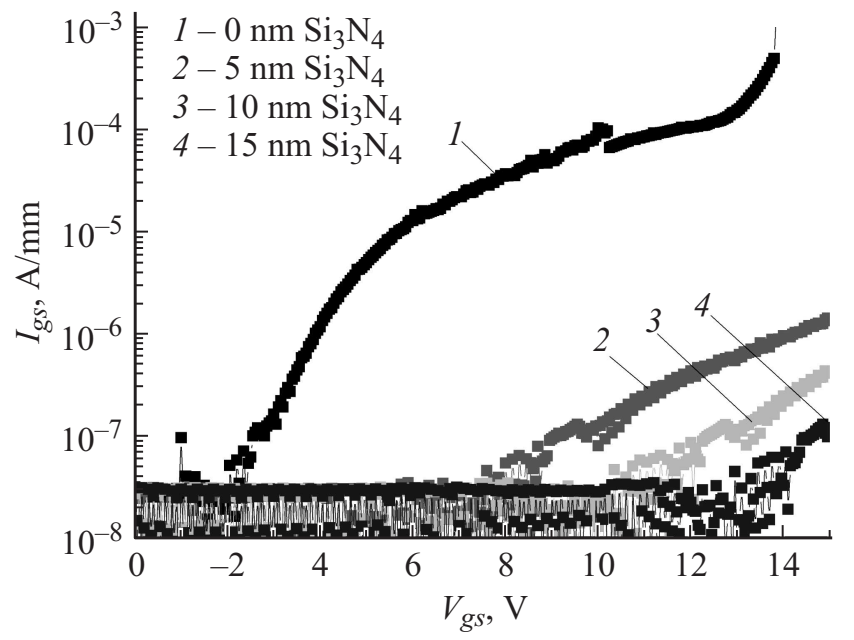

Рис. 3. Затворные передаточные характеристики $\left(I_{g s}-V_{g s}\right)$ изготовленного мощного $\mathrm{GaN}$-транзистора с подзатворной областью на основе МДП-структур.

$V_{\text {th }}=+1.5$ В и начального тока стока $I_{d s o}=3$ мкА $/$ мм при $V_{g s}=0 \mathrm{~B}$. Величина максимального тока стока транзистора составляет $I_{d s}=0.52 \mathrm{~A} /$ мм при $V_{g s}=15 \mathrm{~B}$. Из результатов, представленных на рис. 2, видно, что GaN-транзисторы с подзатворной областью на основе МДП-структур с толщинами диэлектрика 5, 10 и 15 нм демонстрируют значения порогового напряжения $V_{\text {th }}=+1.7,+3.8,+6.8$ В соответственно. При этом увеличение толщины подзатворного диэлектрика приводит к снижению начального тока-стока транзистора в закрытом состоянии, что может быть обусловлено снижением плотности поверхностных состояний на границе раздела $\mathrm{SiN} / p-\mathrm{GaN}$ в результате процесса пассивации. Следует отметить, что транзисторы с подзатворной МДП-областью с толщиной диэлектрика 15 нм демонстрируют меньшую величину максимального тока стока транзистора $I_{d s}=0.25 \mathrm{~A} / \mathrm{Mм}$ при $V_{g s}=15 \mathrm{~B}$.

На рис. 3 представлены затворные передаточные характеристики $\left(I_{g s}-V_{g s}\right)$ изготовленного мощного $\mathrm{GaN}$-транзистора с подзатворной областью на основе МДП-структур. Транзистор, изготовленный классическим способом с затвором на основе барьера Шоттки, характеризуется большой величиной затворного тока $I_{g s}=20$ мкА/мм при $V_{g s}=6 \mathrm{~B}$. Из результатов, представленных на рис. 3, видно, что осаждение тонкой пленки диэлектрика (5 нм) на подзатворную $p$-GaN область транзистора приводит к значительному снижению затворного тока транзистора в открытом состоянии, а также увеличению диапазона максимального рабочего напряжения затвор-исток до $V_{g s}=12-15$ В. При этом увеличение толщины пленки подзатворного диэлектрика до 15 нм приводит к дальнейшему уменьшению тока затвор-исток до уровня $I_{g s}=0.1$ мкА/мм при $V_{g s}=15 \mathrm{~B}$.

На рис. 4 представлены экспериментальные зависимости порогового напряжения отпирания транзистора, с подзатворной МДП-областью, а также его максимального тока-стока от толщины подзатворного диэлектрика.
Данные рис. 4 свидетельствую о том, что увеличение толщины подзатворного диэлектрика с 0 до 15 нм приводит к росту величины порогового напряжения отпирания транзистора с $V_{\text {th }}=+1.5 \mathrm{~B}$ до $V_{\text {th }}=+6.8 \mathrm{~B}$. При этом наблюдается линейное уменьшение максимального тока стока транзистора.

На рис. 5 представлена эквивалентная схема изготовленного мощного GaN-транзистора с подзатворной областью на основе МДП-структур. Известно, что слой $p$-GaN, легированный магнием на поверхности барьерного слоя на основе $\mathrm{AlGaN}$, а также канальный слой $i$-GaN-транзистора, представляют собой $p-i-n$-диод, который открывается подаче положительного смещения на затвор. Барьер Шоттки на поверхности $p$-GaN является обратно смещенным по отношению к $p-i-n$-диоду на

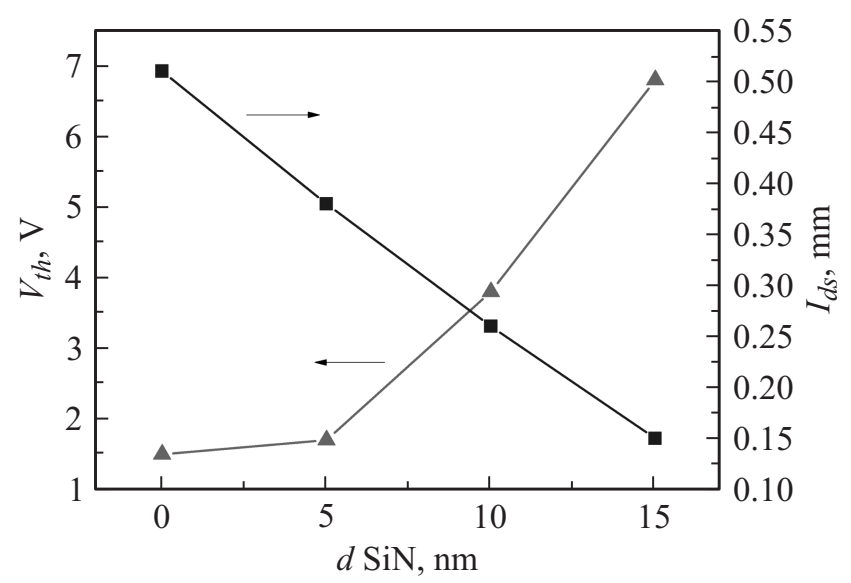

Рис. 4. Экспериментальные зависимости порогового напряжения отпирания GaN-транзистора, с подзатворной МДПобластью, а также его максимального тока стока от толщины подзатворного диэлектрика.

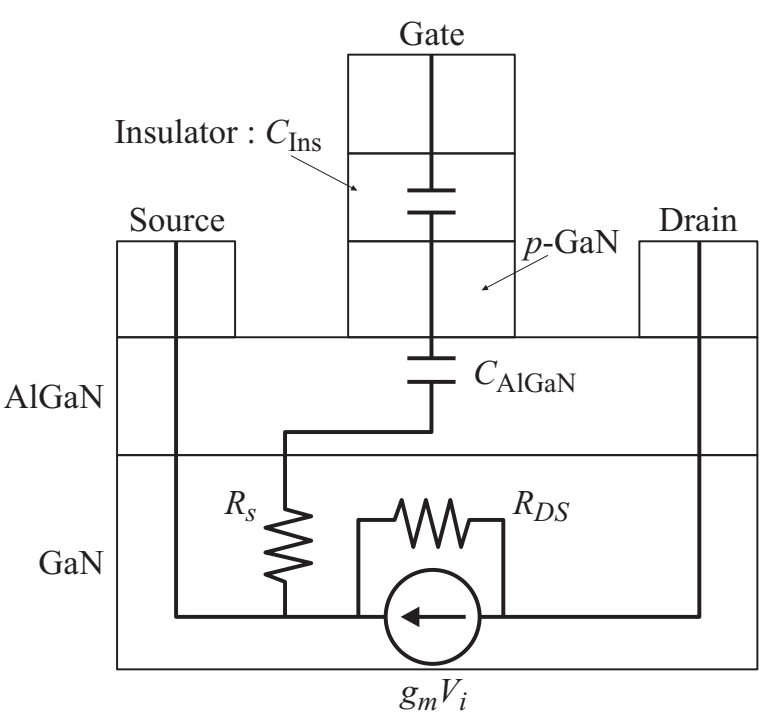

Рис. 5. Эквивалентная схема изготовленного мощного $\mathrm{GaN}$-транзистора с подзатворной областью на основе МДПструктур. 
основе $p$-GaN/AlGaN/GaN. При этом пороговое напряжение отпирания такой структуры определяется емкостью барьерного слоя на основе AlGaN. Введение в состав транзистора подзатворного диэлектрика приводит к увеличению суммарной емкости подзатворной МДПобласти, что и приводит к росту порогового напряжения отпирания мощного GaN-транзистора.

\section{4. Заключение}

Мощные GaN-транзисторы на основе эпитаксиальных гетероструктур $\mathrm{AlGaN} / \mathrm{GaN}$, работающие в режиме обогащения, являются перспективной элементной базой для создания устройств силовой электроники следующего поколения. Для получения нормально закрытных $\mathrm{GaN}$-транзисторов чаще всего используется подзатворная область на основе $p$-GaN слоя. При этом оптимизация его толщины и уровня легирования позволяет достичь величины порогового напряжении отпирания транзистора $V_{\text {th }}=+2 \mathrm{~B}$.

В данной работе показано, что использование подзатворной МДП-структуры в составе $p$--GaN-транзистора приводит к увеличению порогового напряжения отпирания до $V_{\text {th }}=+6.8$ В. При этом данное значение в широком диапазоне будет определяться толщиной подзатворного диэлектрика. Кроме того, установлено, что использование МДП-структуры приводит к уменьшению начального тока $\mathrm{GaN}$-транзистора, а также затворного тока в открытом состоянии, что позволит уменьшить потери энергии при управлении мощными GaN-транзисторами.

Авторы работы выражают благодарность коллективу Научно-производственного комплекса „Микроэлектроника“ АО Научно-производственной фирмы „Микран“ и коллективу Научно-образовательного центра „Нанотехнологии“ Томского государственного университета систем управления и радиоэлектроники за содействие в проведении экспериментальной части работы и обсуждении результатов.

Работа выполнена при финансовой поддержке Министерства образования и науки РФ (соглашение № 14.577.21.0204 от 27.10.15). Уникальный идентификатор проекта RFMEFI57715X0204.

\section{Список литературы}

[1] D. Marcon, B. De Jaeger, S. Halder, N. Vranckx, G. Mannaert, M. Van Hove, D. Decoutere. IEEE Trans. Semicond. Manufacturing, 26, 3 (2013).

[2] O. Hilt, A. Knauer, F. Brunner, J. Würfl. Proc. 22nd Int. Symp. on Power Semiconductor Devices and ICs (Hiroshima, Japan, March 16-18, 2010).

[3] Y. Uemoto, M. Hikita, H. Ueno, H. Matsuo, H. Ishida, M. Yanagihara, T. Ueda, D. Ueda, T. Tanaka. IEEE Trans. Electron. Dev., 54, 7 (2007).

[4] Woojin Choi, Ogyun Seok, Hojin Ryu, Ho-Young Cha, Kwang-Seok Seo. IEEE Electron Dev. Lett., 35, 2 (2014).
[5] D. Bisi, M. Meneghini, M. Van Hove, D. Marcon, S. Stoffels, T. Wu, S. Decoutere, G. Meneghesso, E. Zanoni. Phys. Status Solidi A, 212, 1122 (2015).

[6] P. Lagger, C. Ostermaier, D. Pobegen, D. Pogany. Proc. IEEE Int. Electron Devices Meating (IEDM), 13.1 (2012).

[7] D.V. Kiseleva, Y.N. Yurjev, Y.V. Petrakov, D.V. Sidelev, D.V. Korzhenko, E.V. Erofeev. J. Phys.: Conf. Ser., 789, 012028 (2017).

[8] P. Lagger, M. Reiner, D. Pogany, C. Ostermaier. IEEE Electron Dev., 61, 4 (2014).

[9] M. Meneghini, I. Rossetto, D. Bisi, M. Ruzzarin, M. Van Ho, S. Stoffels, T.-KiWu, D. Marcon, S. Decoutere, G. Meneghesso, E. Zanoni. IEEE Electron Dev. Lett., 37, 12 (2016).

[10] T. Wu, D. Marcon, B. De Jaeger, M. Van Hove, B. Bakeroot, S. Stoffels, G. Groeseneken, S. Decoutere, R. Roelofs. Proc. IEEE Int. Reliability Physics Symp. (Monterey, CA, USA, 2015).

Редактор Г.А. Оганесян

\section{High voltage MIS-gated GaN transistors}

\author{
E.V. Erofeev ${ }^{1}$, I.V. Fedin ${ }^{1}$, V.V. Fedina ${ }^{2}$, \\ M.V. Stepanenko ${ }^{2}$, A.V. Yuryeva ${ }^{3}$
}

${ }^{1}$ Research Institute

of Electrical Communication Systems

of Tomsk State University of Control

Systems and Radioelectronics,

634050 Tomsk, Russia

${ }^{2}$ Research \& Production Company Micran,

634041 Tomsk, Russia

${ }^{3}$ Physical Technical Institute

of National Research Tomsk Polytechnic University, 634050 Tomsk, Russia

\begin{abstract}
E$-mode $\mathrm{AlGaN} / \mathrm{GaN}$ HEMTs are generally promising candidate for switching power transistors due to their high breakdown voltage, high current density and low on-resistance. The threshold voltage $\left(V_{\text {th }}\right)$ of normally-off mode AlGaN/GaN HEMTs with a self-aligned $p$-type GaN gate can be successfully improved by inserting a $\mathrm{SiN}$ insulator between the $p-\mathrm{GaN}$ and a Schottky gate electrode. The $V_{\text {th }}$ can be increased from $+1.5 \mathrm{~V}$ to $+6.8 \mathrm{~V}$ by inserting of $15 \mathrm{~nm} \mathrm{SiN} \mathrm{layer.} \mathrm{Moreover,} \mathrm{the} \mathrm{sub-}$ threshold drain and on-state gate currents of $p$-gate GaN transistor were decreased.
\end{abstract}

